\title{
Vaginal Anastomotic Leakage
}

National Cancer Institute

\section{Source}

National Cancer Institute. Vaginal Anastomotic Leakage. NCI Thesaurus. Code C78698.

Leakage due to breakdown of a vaginal anastomosis. 